07,16

\title{
Модуль Юнга композита zigzag УНТ/графен при растяжении вдоль оси графена
}

\author{
(C) А.С. Колесникова ${ }^{1}$, И.А. Баранов ${ }^{2}$, М.М. Мазепа ${ }^{3}$ \\ ${ }^{1}$ Саратовский государственный университет, \\ Саратов, Россия \\ ${ }^{2}$ ФГКУ „Войсковая часть 11380“, \\ Краснодарский край, Россия \\ ${ }^{3} \mathrm{OOO} \mathrm{„Мирантис} \mathrm{ИТ“,}$ \\ Саратов, Россия \\ E-mail: Kolesnikova.88@mail.ru
}

Поступила в Редакцию 15 мая 2020 г.

В окончательной редакции 15 мая 2020 г.

Принята к публикации 15 мая 2020 г.

\begin{abstract}
Теоретически исследован модуль Юнга конечноразмерный колонного графена на основе zigzag углеродных нанотрубок в виде наноленты. Исследована зависимость упругих свойств от структурных параметров колонного графена - длины и диаметра углеродных нанотрубок, входящих в состав композита. При этом в пределах одного композита структурные параметры углеродных нанотрубок оставались постоянными. Установлено, что величина модуля Юнга увеличивалась с увеличением длин углеродных нанотрубок. Модуль Юнга для композитов с увеличением диаметра уменьшается.
\end{abstract}

Ключевые слова: колонный графен, модуль Юнга, киральность углеродных нанотрубок, наноленты.

DOI: 10.21883/FTT.2020.10.49920.109

\section{1. Введение}

В настоящее время предполагается, что одним из наиболее перспективных материалов для наноустройств будет композит колонный графен, состоящий из углеродных наноторубок (УНТ) и графена. Выбор данного материала обусловлен преимуществом, заключающемся в его гибкости [1]. Данные композиты являются трехмерными структурами с вертикально выровненными относительно графена углеродными нанотрубками, связанными ковалентными связями с верхним слоем многослойного графенового листа. При образовании композита края УНТ остаются открытыми, а в графеновом листе, к которому присоединяется УНТ, образуется отверстие, форма и размер которого соответствуют диаметру присоединенных нанотрубок [2]. В ряде институтов (Rice University - Houston, Texas Honda Research Institute) успешно синтезированы так называемые „бесшовные“ нанотрубно-графеновые композитные материалы, которые характеризуются высокой электронной проводимостью и омическим контактом между нанотрубками и графеном. Омический контакт возникает из-за ковалентных связей между нанотрубками и графеном, что и делает материал бесшовным. Подобные композиты активно синтезируются методом осаждения паров с использованием летящего катализатора [3-7].

Активно проводятся исследования электронных [8], механических [9-20] и теплопроводящих $[13,14,18,21,22]$ свойств колонного графена. Проводятся эксперименты, в ходе которых структуры колонного графена под- вергаются различным деформирующим нагрузкам. Механические свойства каркасных углеродных структур изменяются в зависимости от геометрии и конфигурации структурных элементов [9-20]. Прочностные свойства колонного графена отличаются для структур с разной киральностью $[13,14]$, длиной $[15,16,18,20]$ или диаметром УНТ $[12,13,18,19]$, расстояниями между УНТ [15-17]. Данные композиты используются в качестве элементной базы для фильтров $[23,24]$ и суперконденсаторов [25].

Для расширения областей применения композитов необходимо подробнее исследовать их свойства. Несмотря на активное исследование механических свойств подобных композитов, во всех этих работах рассматриваются композиты, составной частью которых является armchair УНТ. Работ, связанных с исследованием механических свойств композитов, содержащих zigzag УНТ, не найдено. Выбор zigzag УНТ композитов обусловлен их проводящими свойствами, которые являются важной характеристикой для устройств наноэлектроники.

Целью настоящей работы является теоретическое исследование модуля Юнга конечноразмерного колонного графена на основе zigzag УНТ в виде наноленты. Исследована зависимость упругих свойств от структурных параметров колонного графена - длины и диаметра УНТ, входящих в состав композита. В рамках настоящей работы структурные параметры в пределах одного композита оставались постоянными. Однако для серии композитов изменялись структурные параметры УНТ. 
Размеры графенового полотна в серии квадратных композитов

\begin{tabular}{|c|c|c|c|c|c|}
\hline \multirow{2}{*}{$\begin{array}{l}\text { Диаметр } \\
\text { УНТ, А }\end{array}$} & \multirow{2}{*}{$\begin{array}{c}\text { Длина торца } \\
\text { zigzag, } \AA\end{array}$} & \multicolumn{4}{|c|}{$\begin{array}{c}\text { Длина торца armchair графенового полотна } \\
\text { при изменении количества УНТ, } \AA\end{array}$} \\
\hline & & 2 УНТ & 4 УНТ & 6 УНТ & 8 УНТ \\
\hline $\begin{array}{r}5 \\
15\end{array}$ & $\begin{array}{l}16.4 \\
26.6\end{array}$ & $\begin{array}{l}33.5 \\
51.1\end{array}$ & $\begin{array}{r}68.5 \\
103.7\end{array}$ & $\begin{array}{l}103.5 \\
156.3\end{array}$ & 138.5 \\
\hline
\end{tabular}

\section{2. Объект исследования}

В рамках настоящей работы рассматривались композиты в виде нанолент. Все исследованные композиты отличались геометрическими параметрами. Для моделирования многослойного графенового листа использовался один графеновый лист с жестко закрепленными атомами, с которым на ван-дер-Ваальсовом расстоянии располагался композит, образованный вертикально ориентированными углеродными нанотрубками относительно графеного листа. УНТ связаны ковалентными связями с графеновым листом, в котором имеются отверстия, форма и размер которых соответствует диаметру присоединенных нанотрубок.

Исследованы композиты на основе УНТ с диаметром $5,15 \AA$. Длины УНТ в серии для всех диаметров изменялись с 3.2 до $31 \AA$.

Для каждого ленточного композита в серии:

1. Количество УНТ изменялось вдоль торца armchair, а вдоль торца графенового полотна zigzag располагалась одна УНТ.

2. Длина и диаметр всех УНТ были одинаковыми.

3. Расстояние между стенками УНТ составило $12 \AA$.

Геометрические размеры построенных ленточных моделей колонного графена представлены в таблице.

\section{3. Модуль Юнга композита zigzag УНТ/графен при растяжении вдоль оси графена}

В работе [26] проведена оценка влияния формы композита на его модуль Юнга и на основе численных экспериментов получены следующие результаты:

1. Значения модуля Юнга увеличиваются с увеличением длин УНТ в композите независимо от формы и размеров графенового полотна композита.

2. При увеличении длины УНТ до $3.2 \mathrm{~nm}$, а также размера графенового листа по одной из сторон до $6.85 \mathrm{~nm}$ значение модуля Юнга стремится к $180 \mathrm{GPa}$ для квадратичных и ленточных композитов.

В рамках данной работы проводились исследования ленточных композитов с УНТ диаметром 5 и $15 \AA$ с целью определить, как влияет диаметр УНТ композита на значение модуля Юнга. Зависимость модуля Юнга ленточного zigzag-колонного графена от длин УНТ и размеров графенового полотна для композитов с диаметром УНТ 5 и $15 \AA$ представлена на рис. 1 и 2.

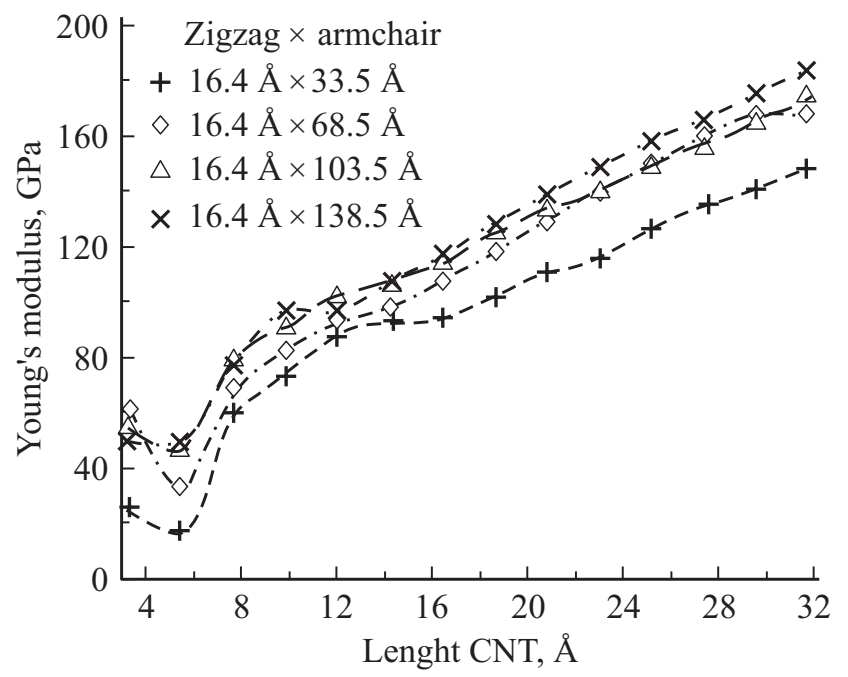

Рис. 1. График зависимости величины модуля Юнга для ленточных композитов с УНТ диаметром $5 \AA$. В легенде указаны размеры графенового полотна.

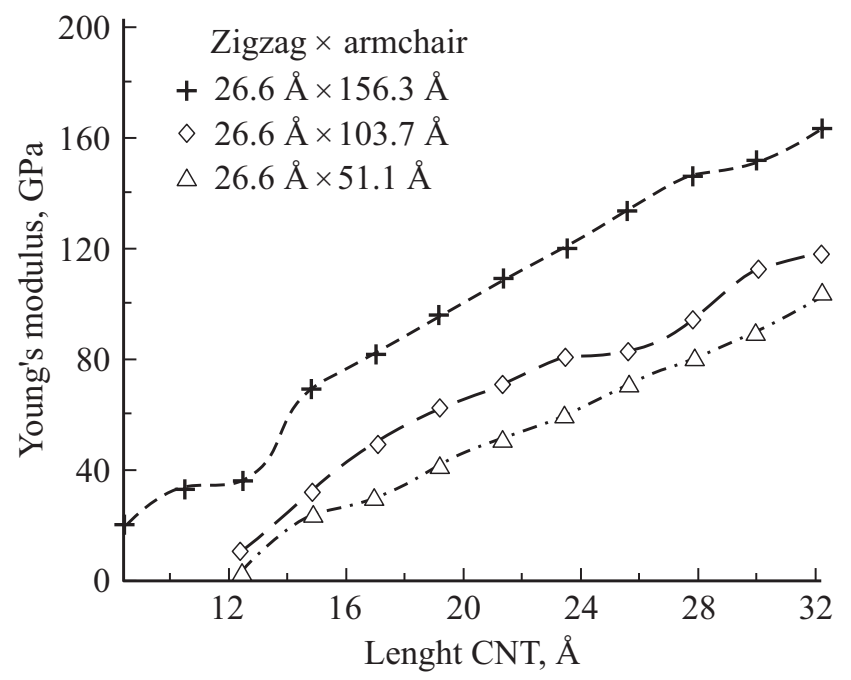

Рис. 2. График зависимости величины модуля Юнга для ленточных композитов с УНТ диаметром 15 А̊. В легенде указаны размеры графенового полотна.

Из работы [19] известно, что модуль Юнга уменьшается в зависимости от диаметра УНТ в композите. Проведенные в данной статье исследования согласуются с результатами исследований, представленными в работе [19]. В связи с этим, при сравнении данных на 
рис. 1 и 2 видно, что модуль Юнга для композитов, содержащих УНТ с большим диаметром, уменьшился на 11\%. При этом, ширина графенового листа увеличивалась пропорционально увеличению диаметра УНТ в композите.

Полученные результаты качественно и в порядках совпали с результатами для многослойных столбчатых композитов, многослойных протяженных armchairкомпозитов [19], однослойных протяженных armchairкомпозитов [23] и конечно-размерных armchair-композитов [18].

\section{4. Выводы}

В рамках настоящей работы впервые проведено исследование модуля Юнга колонного графена в зависимости от длин и диметров zigzag УНТ, размеров графенового полотна. Исследование проведено для композитов с УНТ диаметром 5 и $15 \AA$, длины УНТ изменялись в пределах от 3.2 до $31 \AA$. Размеры графенового полотна изменялись в соответствии с изменением количества УНТ в композите. Для квадратных композитов количество УНТ вдоль zigzag-торца соответствовало количеству УНТ вдоль armchair торца. В случае ленточных композитов, исследованы структуры, в которых вдоль торца zigzag располагалась одна УНТ.

Рассчитаны теоретические значения модуля Юнга при растяжении исследованных структур на 3\% вдоль нормали к центру графенового полотна. Получены следующие результаты:

1. Во всех композитах, исследованных с учетом влияния подложки, величина модуля Юнга увеличивалась с увеличением длин УНТ в композите.

2. При исследовании композитов с диаметрами $5 \AA$ выявлено, что величина модуля Юнга увеличивается с увеличением размеров графенового полотна в композите до $6.8 \mathrm{~nm}$, хотя бы по одной из сторон (zigzag или armchair) графенового полотна. Однако дальнейшее увеличение полотна не приводит к увеличению модуля Юнга композита.

3. При исследовании композита с диаметром УНТ $15 \AA$ установлено, что модуль Юнга уменьшился на 11\% по сравнению с модулем Юнга композита с диаметром УНТ $5 \AA$ несмотря на то, что ширина графенового листа увеличивается пропорционально увеличению диаметра УНТ в композите.

4. При увеличении длины УНТ до $3.2 \mathrm{~nm}$, а также размера графенового листа по одной из сторон до $6.85 \mathrm{~nm}$ значение модуля Юнга стремится к $180 \mathrm{GPa}$ для квадратичных и ленточных композитов. Можно сделать вывод, что модуль Юнга не зависит от формы графенового полотна в композите.

\section{Финансирование работы}

Работа выполнена при финансовой поддержке Президентской стипендии 2019-2021 (проект № СП-310.2019.1).

\section{Конфликт интересов}

Авторы заявляют, что уних отсутствует конфликт интересов.

\section{Список литературы}

[1] P. Dong, Y. Zhu, J. Zhang, F. Hao, J. Wu, S. Lei, H. Lin, R.H. Hauge, J.M. Tour, Jun Lou. J. Mater. Chem. A 2, 20902 (2014).

[2] S. Vadahanambi, S.H. Lee, W.J. Kim, I.K. Oh. Environ. Sci. Technol. 47, 10510 (2013).

[3] Y. Zhu, L. Li, C. Zhang, G. Casillas, Z. Sun, Z. Yan, G. Ruan, Z. Peng, A.R.O. Raji, C. Kittrell, R.H. Hauge, J.M. Tour. Nature Commun. 3, 1225 (2012).

[4] D. Kondo, S. Sato, Y. Awano. Appl. Phys. Exp. 1, 074003 (2008).

[5] V.A. Labunov. Semicond. Phys. Quantum Electron. \& Optoelectron. 13, 137 (2010).

[6] F. Du, D. Yu, L. Dai, S. Ganguli, V. Varshney, A.K. Roy. Chem. Mater. 23, 4810 (2011).

[7] V. Jousseaume, J. Cuzzocrea, N. Bernier, V.T. Renard. Appl. Phys. Lett. 98, 123103-1 (2011).

[8] R. Shahsavari, N. Sakhavand. Carbon 95, 699 (2015).

[9] A.S. Kolesnikova, M.M. Mazepa. Proc. SPIE. 10508, 105080N (2018).

[10] M. Moradi, J.A. Mohandesi. AIP Adv. ]bf5, 117143 (2015).

[11] K. Duan, Y. Li, L. Li, Y. Hu, X. Wang. Mater. Des. 147, 11 (2018).

[12] C.H. Wang, T.H. Fang, W.L. Sun. J. Phys. D 47, 405 (2014).

[13] T.H. Fang, W.J. Chang, Y.C. Fan, W.L. Sun. Jpn J. Appl. Phys. 55, 040301 (2016).

[14] K. Xia, H.Zhan, Y. Wei, Y.Gu. Beilstein J. Nanotechnol. 5, 329 (2014).

[15] S. Sihn, V. Varshney, A.K. Roy, B.L. Farmer. Carbon 50, 603 (2012).

[16] Y.C. Wang, Y.B. Zhu, F.C. Wang, X.Y. Liu, H.A. Wu. Carbon 118, 588 (2017)

[17] L. Xu, N. Wei, Y. Zheng, Z. Fan, H.Q. Wangac, J.C. Zheng. J. Mater. Chem. 22, 1435 (2012).

[18] L. Song, Z. Guo, G.B. Chai, Z. Wang, Y. Li, Y. Luan. Carbon 140, 210 (2018).

[19] A.S. Kolesnikova, M.M. Mazepa. Phys. Solid State 60, 1827 (2018).

[20] J. Shi, Y. Dong, T. Fisher, X. Ruan. J. Appl. Phys. 118, 044302 (2015).

[21] V. Varshney, A.K. Roy, S.S. Patnaik, G. Froudakis. ACS Nano. 4, 1153 (2010).

[22] Y. Zhu, L. Li, C. Zhang, G. Casillas, Z. Sun, Z. Yan, G. Ruan, Z. Peng, A.R.O. Raji, C. Kittrell, R.H. Hauge, J.M. Tour. Nature Commun. 3, 1 (2012).

[23] V. Varshney, S.S. Patnaik, A.K. Roy, G. Froudakis, B.L. Farmer. ACS Nano 4, 1153 (2010).

[24] J. Lin, C. Zhang, Z. Yan, Y. Zhu, Z. Peng, R.H. Hauge, D. Natelson, J.M. Tour. Nano Lett. 13, 72 (2013).,

[25] A.V. Eletskii, G.S. Bocharov. Plasma Sources Sci. Technol. 18, 034013 (2009)

[26] A.S. Kolesnikova, M.M. Mazepa, I.V. Kirillova, L.Yu. Kossovich. Proc. SPIE 10893, Reporters, Markers, Dyes, Nanoparticles, and Molecular Probes for Biomedical Applications XI. 108930, 108930T (2019).

Редактор К.В. Емцев 